\title{
Designing for Revitalization of Communities through New Business Models for Traditional Arts and Crafts
}

\author{
Tao Huang1, Eric Anderson ${ }^{2}$ \\ ${ }^{1}$ Southern Illinois University, Carbondale, USA \\ ${ }^{2}$ Resilient Farms and Design Studio, Makanda, USA \\ Email: thuang@siu.edu, resilientdesignchicago@gmail.com
}

How to cite this paper: Huang, T., \& Anderson, E. (2019). Designing for Revitalization of Communities through New Business Models for Traditional Arts and Crafts. Art and Design Review, 7, 225-236. https://doi.org/10.4236/adr.2019.74018

Received: October 11, 2019

Accepted: November 2, 2019

Published: November 5, 2019

Copyright () 2019 by author(s) and Scientific Research Publishing Inc. This work is licensed under the Creative Commons Attribution International License (CC BY 4.0).

http://creativecommons.org/licenses/by/4.0/

\section{c) (i) Open Access}

\begin{abstract}
This paper discusses the importance and opportunities of design in helping to revitalize rural and marginalized communities where traditional arts and craft businesses often reside. It argues that traditional arts and craft businesses need to build a symbiotic relationship with the local communities to ensure the survival and thriving of both. It aims to demonstrate that designers should and can work traditional arts and craft business to better tell their stories and pursue new business opportunities with the goal to achieve sustainable development of these businesses and their communities. Through ethnography research and participatory design process, the paper presents the research team's collaborations with a few traditional arts and crafts business owners in three communities and presents a few design concepts resulted from this process. It provides a list of suggestions based on the above analysis for designers who are interested in working as the link between business and traditional arts and design.
\end{abstract}

\section{Keywords}

Revitalization, Business Model, Cultural Heritage, Rural Communities, Co-Design

\section{Introduction}

\subsection{Crisis of Traditional Arts and Crafts}

Traditional arts and crafts can be considered as the bridge between our material and non-material cultural heritage. Sadly, the accelerating disappearance of hand-crafted objects in the era of mass manufacturing is undeniably apparent. The reasons behind this phenomenon are multifold. Economically, the tradi- 
tional arts and crafts business have been struggling to make a profit in the era of mass production due to its inherently high labor costs. The products from these trades such as Russian Palekh lacquer miniatures are considered luxury items from a bygone era, which do not seem to be of too much use in the day-to-day life (Khaire, 2019). In addition, many traditional products can be easily and cheaply replaced by mass-produced products such as bamboo weaving baskets. Thus, traditional arts and crafts have become an unattractive career path for the younger generations, being dismissed as "old-fashioned" or "difficult to learn" (Bazenkova, 2015; Bratley, 2010). This "inheritance crisis" hinders the preservation and development of these trades.

Beyond these practical reasons, we believe there is a deeper social and cultural reason for their loss: the disconnection between communities and the environment they live in. The cultural heritage, symbolic meanings, and techniques embodied by traditional arts and crafts reflect the local ecology and environment are gradually becoming less relevant in a globalized world. In addition, young people are leaving rural area in droves to cities to seek higher paying jobs. As a result, many traditional arts and crafts trades in rural area find it more difficult to attract new workers and customers. As these trades diminish, so do the communities that bred them. Therefore, revitalizing traditional arts and crafts business is not a simple matter of improving efficiency or reducing costs, or incorporating these aesthetics into new products. Indeed, if our aim is preservation of our unique cultural heritage, the sustainable solution is to retell the story of the unique cultural backgrounds of traditional arts and crafts and connect them with new generations of consumers and makers. While goods produced by traditional arts and crafts can be updated for modern use, there needs to be new business strategies that will create interesting and authentic memories associated with the goods that the traditional arts and crafts trades produce. These memories should be culturally relevant to the local communities, thus, encouraging or stimulating the community's desire to preserve them. People ought to be proud of their traditions. In turn, consumer support for these businesses will help these communities to thrive again.

Ensuring the survival and continued development of these arts is not a simple matter because the economic, cultural, and social environment for these goods has all dramatically changed in the past hundred years, especially so in fast developing countries with rich cultural heritages like China and India. The paper argues that we should not only preserve traditional arts and crafts in museums, but also to create a healthy "eco-system" for them to continue to exist in the society as functional objects as well as cultural symbols so that artisans and craftsmen can continue to generate sustainable economic interests for their work and contribute to their communities.

Paradoxically, design can play a crucial role in linking traditional arts and crafts with economic development because of its enormous power to communicate at a massive scale. Design thinking methods can be utilized in finding ways 
to resolve this complex problem that might involve product development, brand building, business and tourism planning, service design, and much more.

\subsection{The Role of Design}

Designers' responsibilities have gone beyond merely creating functional and eye-catching artefacts. Design has become an important instrument for building business and social strategies to bring about great cultural and economic changes. Ezio Manzini \& Coad (2015) stated that: "Cultural activists, grassroots organizations, and design activists are converging towards a range of initiatives whose purpose is not to offer immediate solutions to problems, but to spark interest in these areas and show, often paradoxically or provocatively, that there are different ways of seeing and resolving them. (p. 46)". Bernardo Calzadilla-Sarmiento, Director of United Nations Industrial Development Organization's Department of Trade, Investment and Innovation, also pointed out: "Industrial design, through innovation and creativity, is essential to attain the objectives of the 2030 Development Agenda and its 17 Sustainable Development Goals, and especially Goal 9 on infrastructure, innovation, and sustainable industrialization." (UNIDO, 2019).

The recognition of this power of design in both private and public sectors leads to policy changes in many countries. The Ministry of Industry and Information Technology of the Chinese Government released the "Design for Poverty Alleviation Action Plan" in 2018, which covers many areas in the development of marginalized communities. Reviving traditional arts and crafts was identified as one of the core strategies for this redevelopment. Under this directive, the China Industrial Design Association (CIDA) subsequently issued ten design strategies. From CIDA's documents, the following business strategies for traditional arts and crafts can be summarized (CIDA, 2019):

- Establish a design-centered new industry chain for traditional industry.

- Create new values for traditional industry through design.

- Enhance consumer experience for traditional business through design.

In these documents, several successful cases were presented.

\subsection{Design for a New Experience}

Memories are created through experience. In their book, Pine and Gilmore (2011) defined the economic offerings of a business in four categories: commodity, goods, service, and experience. They argued that a rich and compelling experience is the most desirable for consumers in the $21^{\text {st }}$ Century. While most traditional artisans and craftsmen are not in the service industry, they provide services to their clients at many "touch points" (encounters with the clients) to meet their needs. Many traditional arts and crafts businesses are also small non-employer businesses (have no employees except the owners). For any small business, the quality of its service is what its proprietors rely upon to differentiate the business from larger well-established brands. Literature reveals 
that face-to-face communication and personal relationship with customers are very important to small business (Holzer \& Sapsford-Francis, 2010; Wiswall, 2009). To grow repeat customers, traditional arts and crafts business must create a culturally relevant experience that people want to come back to, not just to purchase goods and services. Designers (broadly referred to industrial designers, fashion designers, graphic designers, as well as architects) with their expertise in mass communication and user-centered design methods can partner with these artisans and craftsmen to explore new business opportunities to create exciting new experience.

The destinies of traditional arts and crafts and the soil that "grew" them are intertwined. The ideas and techniques might be non-material, while the artefacts resulting from these practices stand as a testimonial to the humankind's rich history and diverse cultural beliefs. We are convinced that the most promising strategy for preserving and developing traditional arts and crafts business is to make them a driving force behind the revitalization and development of marginalized rural communities. The approach must be systematic and interdisciplinary and any research efforts must be conducted not in labs, but within the communities.

Clearly, now is the perfect time for designers to work with traditional arts and crafts businesses towards the ultimate goal of revitalizing depressed communities. Many designers have been working in the field, most recently, Japanese Amezaiku Hanakawado Studio, Fendi of Italy (Povoledo, 2018) and Safina Projects CIC (to revive traditional boat building techniques in Iraq) (Safina Projects CIC, 2017). However, few theoretical studies have been conducted on this subject because long term economic benefits of design's involvement in revitalizing traditional arts and craft and marginalized communities are difficult to calculate. Albeit, more such studies should emerge in the next decade due to the policy changes mentioned above. This paper discusses several cases that our design team has been involved with and attempts to distill a set of principles useful for designing for revitalization of culturally significant communities and industries.

\subsection{Research Questions}

Based on literature and preliminary research, the following assumptions were established before the project was started (Huang \& Anderson, 2019):

- First, a multidisciplinary and systematic approach must be taken to generate a wide range of business solutions to revitalize traditional arts and crafts and their surrounding communities;

- Second, design research and design thinking strategies can provide new business ideas for solving complex problems.

Therefore, the research questions become: How can design help tell the story of traditional arts and crafts? What are the opportunities and obstacles that designers must consider when creating new business strategies for traditional arts and crafts businesses? 


\section{Methodology}

\subsection{Locations of Research and Design Activities}

The researchers choose three communities as the primary research locations. These locations are: Makanda, Illinois, USA; Songkou, Fujian Province, China; Orkney, Scotland, UK. These three communities locate on three continents. Although culturally and geographically vastly different, they have many things in common: they are all rural areas that are relatively close to (within two hours by car or ferry) major metropolitan areas (Makanda is close to St. Louis, Songkou is close to Fuzhou, and Orkney is close to Inverness); they have relatively small populations (Makanda has 600 residents, Songkou has 31,000, Orkney has 21,000); and most significantly, they have been the site of an historically significant local and traditional arts and crafts that date back to over 100 years ago. As such, the researchers have worked to establish local contacts and to build working relationships with arts and crafts business owners in these communities.

\subsection{Participatory Design}

Through workshops and ethnographic research (interviews and observations), the research team examined the success and failure of some of these new business ideas. Some of the business owners and community activists in Makanda and Songkou were actively involved in the design process to ensure the design team understood their business' goals and their user scenarios. Likewise, the design team participated in the operation of some of these businesses and their various activities in order to test, improve and validate their design concepts. The research team has also participated in several local arts and craft fairs and training workshops to speak with various local artisans, observe their business handling and customer services, and observe the customers' reactions towards the products and services.

\subsection{Interviews}

Multiple interviews were conducted with designers and local small business owners, which helped the team understand the factors that have contributed to the success and failure of similar business in the past. Interviews were also conducted with potential customers. Since this research project has involved nearly 100 students in a variety of design disciplines and a variety of business owners over several years, and the interviews were mostly conducted in informal settings, the interview questions have been chosen from an evolving list to tailored to the specific businesses and locations. The core questions for the traditional arts and craft business owners and community activists focus on these five aspects:

- Regarding People: Does your practice/business fulfill a local need? Who are your local and global customers?

- Regarding Culture: What are the cultural heritages of your practice? How does your practice/business capitalize on the regional unique characteristics?

- Regarding Environment: Does your business promote local consumption? 
Does your practice/business promote sustainable living?

- Regarding Production: What is unique about your production method? What are the products that best represent your local culture?

- Regarding Space: Does your practice/business create a public space for a civil dialogue about cultural heritage?

\section{Results}

\subsection{Analysis of Data}

Students went through the typical qualitative data analysis process: interview data was compiled to identify keywords and themes (Figure 1); personas (business owners and potential consumers for the business) were created; competitiveness of the businesses and the current market were analysed (Figure 2); user scenarios were generated.

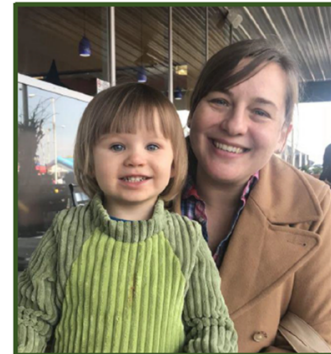

Jennifer W. S. Paulson Executive Director Food Works

- Participants of Farm Crawl:

- Families

- Small farm owners

- Some Students

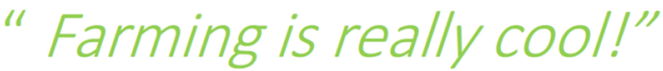

Visitors'feedback

O Your plans for more improvements: $\bigcirc$ Issues in incorporation with schools:

- have places to eat food right there

- Limited capacity

- Add more farms, such as Bison farm

Lack of staff to watch the kids

- College students prefer ready or frozen meal

- Limitations:

- Capacity

- Staff time

- Money

o Students role:

- Most participation of students is in activities related to wineries and breweries.

o Supportive funding:

- $S I H$, Southern Illinois Healthcare

- Experimental Station

- State grants or privet funders.

- Depression problems for kind of being isolated in their farm.

\section{Rural Revitalization}

Figure 1. Interview data was analyzed and insights shown in design presentations (interview of Jennifer Paulson by Dena Hassani).

\section{Strengths}

Genuine artistries

Home-y environment

Near college campus

Friendly owners

Plenty of recreational activities to do around the shop

Opportunities

Expand to younger audience through social media

\section{Weaknesses}

Shop is in the back half of Boardwalk (hard to see)

Mostly known by locals

Low budget, expensive to reach out

Poorly advertised to public

\section{Threats}

Competition: home-made goods is becoming a popular market and there are many vendors

Figure 2. SWOT analysis (interview of David Dardis of Rainmaker Studio by Peyton Schnurr). 
Through these analysises, the design and research team identified several business opportunities and presented them to local communities.

\subsection{Business Opportunities: Design for Unique Cultural Heritage}

For communities like Songkou and Makanda to succeed, designers must create unique offerings based on their cultural heritage to set them apart from others. This is not an easy process as we found that cultural heritage must be cleverly packaged to become a successful product or service that might generate sustainable economic activities.

For instance, the craftsmen of bamboo weaving in Songkou create beautiful but delicate containers that might be easily crushed in transportation, thus it is difficult to market them to tourists or sell them via the internet. We also discovered that the local craftsmen need extensive help to update their products for a more urban audience. The products they produced are well made, but mostly are plain, lacking the design values that people might be willing to pay more for. One of the solutions that our design team presented was to use bamboo weaving baskets as packaging for locally-made snacks (Figure 3). This solution not only creates a new market for the traditional craft products, but also helps to reduce waste associated with packaging materials. Most importantly, it adds value to both the snacks and the bamboo container, resulting in a more culturally and environmentally conscious food product wrapped in an interesting yet practical protective vessel.

Furthermore, we found that these arts and craft trades themselves can be weaved into a compelling and culturally meaningful story of the old town of Songkou. The presence of these artisans and their studios on the main street of the old town of Songkou and Makanda proves to add nostalgic feeling and help to attract tourists. Admittedly, these brick and mortar establishments usually need renovation to provide a better viewing and shopping experience. But this

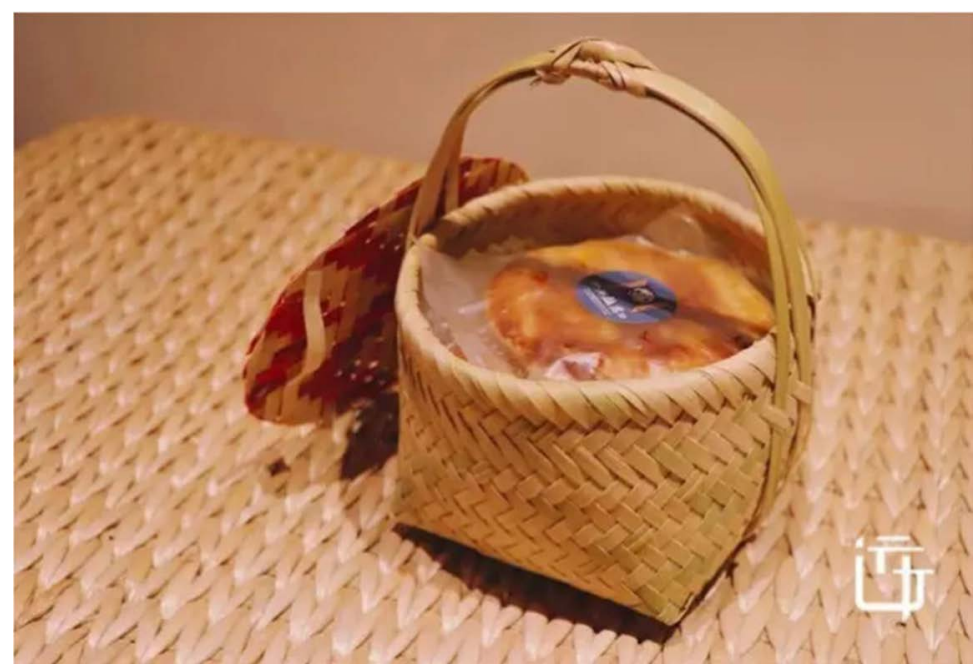

Figure 3. Bamboo basket gift packaging design for Songkou (designed by Wenyi Wu, Yingxuan Wu, and Anyuan Wang). 
investment is justified because integrating these business into the landscape of the town can provide a better cultural experience for both community members and tourists.

One of our design teams decided to take this approach and presented an architectural solution to address the disconnection of the natural environment and the town, as well as the disconnection of history and the present. The Multifunctional Pavilion on the Water in Songkou (Figure 4) reminds people of the important role that the river once played in the history of Songkou (The city used to be a busy port for river transportation). While the primary intention of the pavilion is to increase the interaction between people and nature, it could also be used as a resting area along the river bank, or a fishing dock. At night, the space can be transformed into a performance centre for experiencing local opera (another form of traditional arts). The concept incorporates the architectural language of unique local buildings called "Cuo", as well as the traditional craft of using bamboo as building materials.

For the small and scattered arts and crafts studios in Makanda, the research and design team worked with one of them, a metalsmithing craftsman, to create a new marketing campaign, with the central idea of creating a new tradition by connecting his studio practice with the most notable feature of the area: the town is situated within the heart of the vast Shawnee National Forest. The slogan for the campaign "Capture Nature in its Raw Form" (Figure 5) reflects both the craftsman's practice and its connection with the surrounding areas. These designs exemplify our team's approach to seek or expand business opportunities based on the historic cultural heritage and unique local features.

We also realized that it is important to look beyond the obvious. For instance, in Orkney, we observed that artisans such as jewellery makers and weavers frequently use the surrounding ocean as their theme, or incorporate Celtic or Viking symbols or patterns into their work. While these cultural references are appropriate, the market is already saturated with similar products. We argue that an often ignored core cultural value of many rural communities is their deep

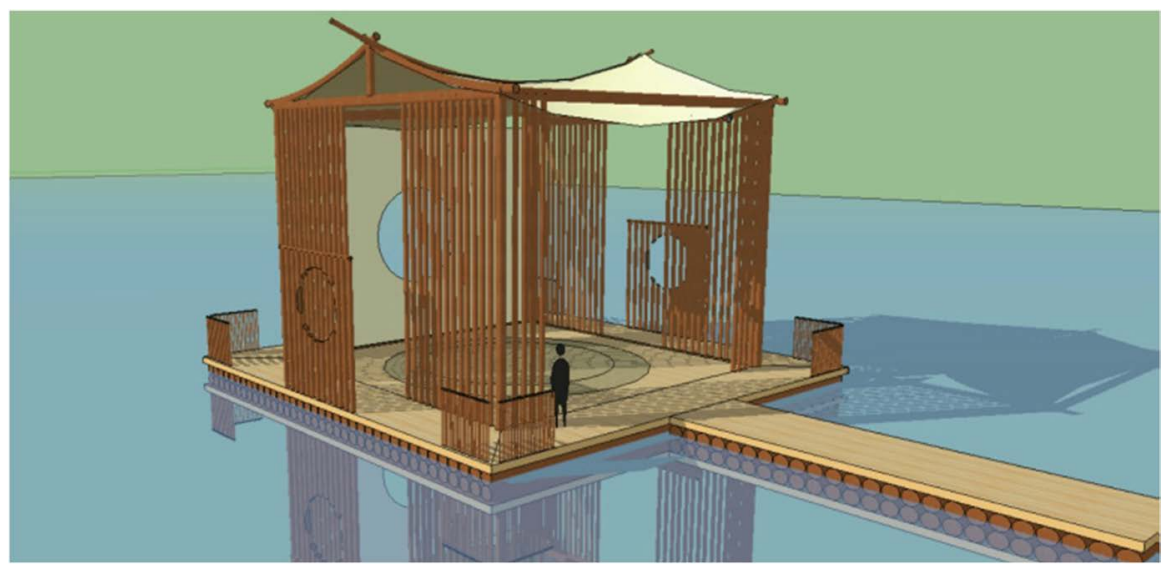

Figure 4. Multifunctional pavilion on the water (designed by Xiaopu Zhou, Shiyun Feng, Qi Qi, and Jiayi Sun). 


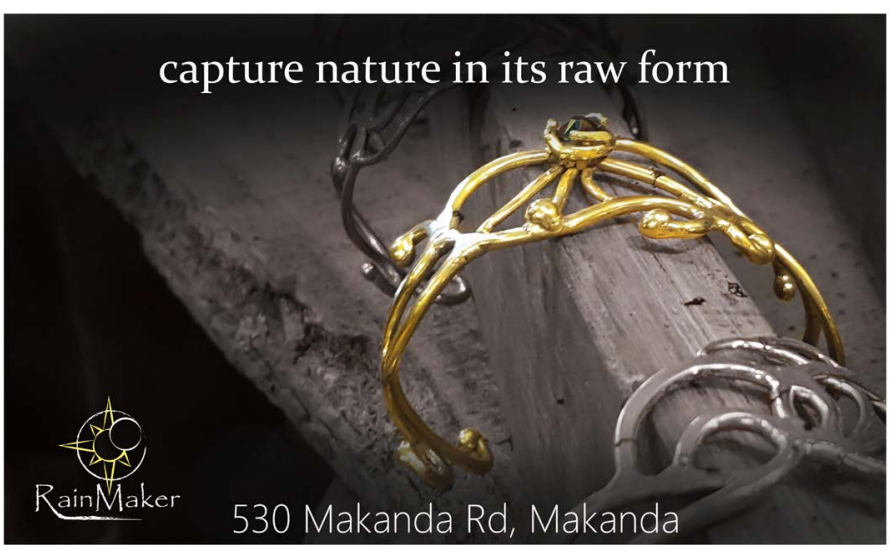

Figure 5. Promotional campaign for Rainmaker Art Grotto (designed by Peyton Schnurr).

concern for the environment. For instance, despite their proximity to the North Sea petroleum fields, Orkney is leading the way for sustainable renewable energy (McKie, 2019). Using biodegradable materials for packaging, sustainable harvesting, upcycling, etc., these environmentally conscious practices can all be a part of the story of traditional arts and crafts in these communities.

\subsection{Business Opportunities: Design for Craft-Tourism}

Tourism is one of the main revitalization strategies for many rural communities (Ammirato \& Felicetti, 2013; Ikerd, 2008; Allen, Van Dusen, Lundy, \& Gliessman, 1991). Traditional arts and crafts can easily fit into this scheme. Songkou opened a Museum of Traditional Life in 2013 and regularly holds workshops to draw visitors to work with local artisans and craftsman to create chopsticks and bamboo weaving decorations. Creative Orkney, an association of craft makers living in the Orkney Islands, created the Creative Orkney Trail in 1995 (Creative Orkney, 2019). Visitors to these islands have a map of these studios and workshops and have the chance to visit and talk directly to the makers. Several potters in the Southern Illinois region (which includes Makanda) started to organize the annual event "Shawnee Hills Pottery Trail" in 2014 to be a part of the overall Shawnee National Forest tourism strategy. The region already promotes the Shawnee Hills Wine Trail of local wineries and this is a fitting addition. By teaming together, these businesses can create a cohesive story to promote the region and their work at the same time (World Tourism Organization, 2018).

Tourism is also about more than selling products (Poon, 1993). It might help tackling the "inheritance crisis". Making arts and craft is often a personal journey. To take the fear out of starting such a journey, experienced artisans and craftsmen can share their love for their craft with new comers in the form of mentorship. Education and entertainment could both be provided if tours and workshops can be offered regularly to attract local visitors, especially families. For individual studios, craft-tourism is also an opportunity to diversify their income stream.

In addition, these experiences could build new traditions. More innovative 
ways are being experimented worldwide. For instance, Rolling Oak Ranch in Makanda, an alpaca farm and weaver studio, started offering yoga with alpaca in June 2019, as a way to attract visitors to their remote location. Neither alpacas nor yoga is part of the historic traditions of Southern Illinois or the Shawnee Forest, but both work well with the emerging tradition of the local eco- and agritourism industries.

\subsection{Business Opportunities: Design for Niche Market}

Dalgic and Leeuw (1994) defined a niche market as "a small market consisting of an individual customer or a small group of customers with similar characteristics or needs". Due to their unique cultural values and higher costs, traditional arts and crafts products must target a specific group of consumers who understand the added cultural values of these trades and are not price-sensitive. For instance, because of the long tradition of hippie culture in the town, Makanda tends to attract customers who are interested in unique, custom, natural, spiritual, and handmade arts and craft products. The local artisans already provide these products, but they need to promote their business better to attract new customers, especially young generations who are not particularly tied to the $60 \mathrm{~s}^{\prime}$ counter-culture movement.

We frequently observed that most small business owners (with the exception of a few) do not have the time nor the tech savvy to create a website or an advertising campaign to promote their businesses. They rely almost solely on digital social platforms such as Facebook or other shared services platforms such as Esty to keep their customers updated. This is a field where designers can quickly intervene. Designers can partner with these entrepreneurs to celebrate the uniqueness of their small businesses by creating contemporary branding and cohesive marketing strategies that include both physical and digital promotional collaterals, therefore refreshing their brand images and helping them connect with new customers.

\section{Suggestions for Designers and Traditional Arts and Craft Business}

Through trial and err, our team has been working on this project for the last three years. Several design principles that might be of use to other design teams have emerged:

- Authenticity is the core value of traditional arts and crafts. Designers should work with their clients to fully understand the symbiotic relationship between the traditional arts and crafts and their local cultures. This helps to avoid creating an experience that is deemed manufactured and therefore appears fake to sophisticated customers.

- While working with small communities, designers should not interfere with their way of life, but rather, aim to improve it for modern comfort. New businesses should not be built on complete abolishment of the old, but to 
take what is good of the old and market it better.

- Designers must work across disciplines and be prepared to find solutions outside of their comfort zone of established professional expertise.

- Selling more stuff is not necessarily the goal of revitalization of traditional arts and crafts and their communities. Raising awareness, increasing appreciation, creating new interests, and exploring new ways to tell the client's stories, should be the long term objective.

\section{Conclusion}

While it may be true that without design and business intervention, traditional arts and crafts will continue to exist as parts of collections in museums around the world, knowledge, appreciation and interest in these objects will increasingly be confined to those narrow specialists. They will be regarded as meaningless by the general public. We believe that it is important to preserve this shared cultural memory. To achieve this objective, these artefacts produced must retain their cultural relevance and be recognized by all as part of our cultural heritage as well as daily lives. Designers can play a critical role in this process by creating a cultural bridge between local artisan and the global citizenry by helping these local businesses remain culturally relevant, by constructing unique educational and interesting experiences that tell compelling stories of the products and the business.

\section{Acknowledgements}

The authors would like to thank the participating students, artists, craftsmen, and business owners. The authors would also like to thank the Far-Near Co. (Guangzhou, China) for organizing group participations in Songkou, and the Open Union Cultural and Creative Co. Ltd. (Taiwan, China) for their guidance for the project.

\section{Conflicts of Interest}

The authors declare no conflicts of interest regarding the publication of this paper.

\section{References}

Allen, P., Van Dusen, D., Lundy, J., \& Gliessman, S. (1991). Integrating Social, Environmental, and Economic Issues in Sustainable Agriculture. American Journal of Alternative Agriculture, 6, 34-39. https://doi.org/10.1017/S0889189300003787

Ammirato, S., \& Felicetti, A. M. (2013). The Potential of Agritourism in Revitalizing Rural Communities: Some Empirical Results. In L. M. Camarinha-Matos, \& R. J. Scherer (Eds.), Collaborative Systems for Reindustrialization. PRO-VE 2013. IFIP Advances in Information and Communication Technology (Vol. 408, pp. 489-497). Berlin, Heidelberg: Springer. https://doi.org/10.1007/978-3-642-40543-3_52

Bazenkova, A. (2015). Crisis Strikes Russia's Traditional Craft Industries. The Moscow Times.

https://www.themoscowtimes.com/2015/07/30/crisis-strikes-russias-traditional-craft-i ndustries-a48664

Bratley, C. M. (2010). Portuguese Handicrafts: A Dying Tradition or a Promising Future? 
The Portugal News.

https://www.theportugalnews.com/news/portuguese-handicrafts-a-dying-tradition-ora-promising-future/2861

CIDA (2019). There Are More Than 10 Design Strategies to Alleviate Poverty. http://www.sohu.com/a/313969183_283830

Creative Orkney (2019). Creative Orkney Creative Trail. https://www.creative-orkney.com/craft-trail/

Dalgic, T., \& Leeuw, M. (1994). Niche Marketing Revisited: Concept, Applications and Some European Cases. European Journal of Marketing, 28, 39-55. https://doi.org/10.1108/03090569410061178

Holzer, S., \& Sapsford-Francis, A. (2010). Sepp Holzer's Permaculture: A Practical Guide to Small-Scale, Integrative Farming and Gardening (1st English Language ed.). White River Junction, VT: Chelsea Green Pub.

Huang, T., \& Anderson, E. (2019). Revitalizing Marginalized Communities for Sustainable Development by Design. Milano, Mexico City, Beijing, Bangalore, Curitiba, Cape Town: Paper Presented at the 3rd LeNS World Distributed Conference.

Ikerd, J. E. (2008). Crisis \& Opportunity: Sustainability in American Agriculture. Lincoln, NE: University of Nebraska Press.

Khaire, M. (2019). Entrepreneurship by Design: The Construction of Meanings and Markets for Cultural Craft Goods. Innovation, 21, 13-32.

https://doi.org/10.1080/14479338.2018.1530566

Manzini, E., \& Coad, R. (2015). Design, When Everybody Designs: An Introduction to Design for Social Innovation. Boston, MA: MIT Press.

http://www.jstor.org/stable/j.ctt17kk7sv https://doi.org/10.7551/mitpress/9873.001.0001

McKie, R. (2019). How Orkney Leads the Way for Sustainable Energy. The Guardian. https://www.theguardian.com/environment/2019/jan/20/orkney-northern-powerhouse -electricity-wind-waves-surplus-power-hydrogen-fuel-cell

Pine, B. J., \& Gilmore, J. H. (2011). The Experience Economy. Boston, MA: Harvard Business Review Press.

Poon, A. (1993). Tourism, Technology, and Competitive Strategies. Wallingford: CAB International.

Povoledo, E. (2018). Teenagers, Forget Engineering. Your Future Is Craft. The New York Times.

https://www.nytimes.com/2018/10/19/fashion/italy-youth-unemployment-fendi-crafts manship.html

Safina Projects CIC (2017). Exploring the Ancient Craft Traditions of Mesopotamia through Art and Design [Web Overview and Progress Report].

https://www.safinaprojects.org/ark-re-imagined

UNIDO (2019). World Industrial Design Conference and the Industrial Design World Expo to Take Place in China.

https://www.unido.org/news/world-industrial-design-conference-and-industrial-desig n-world-expo-take-place-china

Wiswall, R. (2009). The Organic Farmer's Business Handbook: A Complete Guide to Managing Finances, Crops, and Staff- and Making a Profit. White River Junction, VT: Chelsea Green Pub.

World Tourism Organization (2018). UNWTO Annual Report 2017. Madrid: UNWTO. 